\title{
Adoptive immunotherapy combined with FP treatment for head and neck cancer: An in vitro study
}

\author{
MAYAKO NISHIO-NAGAI ${ }^{1}$, SUSUMU SUZUKI $^{2}$, KAZUHIRO YOSHIKAWA $^{3}$, \\ RYUZO UEDA $^{2}$ and YOSHIAKI KAZAOKA ${ }^{1}$
}

\begin{abstract}
${ }^{1}$ Department of Oral and Maxillofacial Surgery, Aichi Medical University; ${ }^{2}$ Department of Tumor Immunology, Aichi Medical University School of Medicine; ${ }^{3}$ Division of Advanced Research Promotion, Institute of Comprehensive Medical Research, Aichi Medical University School of Medicine, Nagakute, Aichi 480-1195, Japan
\end{abstract}

Received June 13, 2017; Accepted September 6, 2017

DOI: $10.3892 /$ ijo.2017.4142

\begin{abstract}
FP treatment, which combines 5-fluorouracil (5-FU) and cisplatin (CDDP) chemotherapy, is widely used for treatment of advanced head and neck cancer (HNC). It has been suggested that these drugs cause immunomodulation in the cancer microenvironment, for example, downregulation of immunosuppressive cells such as regulatory T-cells (Tregs) and myeloid-derived suppressive cells (MDSCs), activating dendritic cells (DCs), and upregulation of tumor antigens and major histocompatibility complex (MHC) molecules in cancer cells leads to enhancement of cancer immunity, which is important in cancer treatment, as well as providing a direct killing effect. Therefore, development of chemoimmunotherapy by combining FP treatment with immunotherapy for $\mathrm{HNC}$ has become a recent challenging issue. However, the direct effects of these drugs on immune effector cells, especially cytotoxic T-lymphocytes (CTLs), are not well known. We have investigated the direct actions of these drugs on CTL functions in in vitro experiments using cytomegalovirus (CMV) pp65 antigen-specific CTLs (CMVpp65-CTLs) and oral squamous cell cancer (OSCC) cell lines overexpressing CMVpp65 antigen as target cells. Although CDDP partially
\end{abstract}

Correspondence to: Dr Susumu Suzuki, Department of Tumor Immunology, Aichi Medical University School of Medicine, 1-1 Yazakokarimata, Nagakute, Aichi 480-1195, Japan

E-mail: suzukis@aichi-med-u.ac.jp

Abbreviations: 5-FU, 5-fluorouracil; B-LCL, Epstein-Barr virustransformed B cell; CDDP, cisplatin; CMV, cytomegalovirus; CTL, cytotoxic T-lymphocyte; DC, dendritic cell; EGFR, epidermal growth factor receptor; HLA, human leucocyte antigen; HNC, head and neck cancer; mAb, monoclonal antibody; MDSC, myeloidderived suppressive cell; MLPC, mixed lymphocyte peptide culture; MHC, major histocompatibility complex; OSCC, oral squamous cell cancer; PBMC, peripheral blood mononuclear cell; Treg, regulatory T-cell

Key words: immunotherapy, cytotoxic T-lymphocyte, 5-FU, CDDP, FP treatment, head and neck cancer, cytomegalovirus inhibited proliferation of memory CMVpp65-CTL in peripheral blood, the proliferation was not inhibited by 5-FU. Cytotoxicity and the IFN- $\gamma$ release response of the CMVpp65CTLs were not inhibited by these drugs, and it is important to note that these drugs, especially 5-FU, sensitized OSCC cell lines to CMVpp65-CTL. Furthermore, CMVpp65-CTL cytotoxicity to CDDP-resistant OSCC cells, HSC-3/CDDP-R1, was the same as the cytotoxicity to the parental cells. Thus, we suggest that combined immunotherapy with FP treatment is an effective novel $\mathrm{HNC}$ treatment.

\section{Introduction}

The annual incidence of head and neck cancer (HNC) is estimated to be between 400,000 and 600,000 new cases, and the mortality rate is between 223,000 and 300,000 deaths per year (1). In Japan, the number of patients affected by HNC was above 24,000 in 2012, and has gradually increased every year (2). Surgery, radiotherapy, chemotherapy and radiochemotherapy are major therapies in HNC. The combination of 5-fluorouracil (5-FU) and cisplatin (CDDP) (FP treatment) is most frequently used in unresectable recurrent and distant metastatic cases (3-6). In addition, a synergetic effect of FP treatment combined with anti-epidermal growth factor receptor (EGFR) antibody, cetuximab, has been reported. It was thus demonstrated that cetuximab plus platinumfluorouracil chemotherapy prolonged both overall survival and progression-free survival as compared with FP therapy alone (7). Despite improvement of the clinical effects, recurrence and distant metastasis occurred in 30 and $25 \%$ of the patients, respectively, and resistance to CDDP was seen in some of the patients $(6,8-10)$. The 5 -year survival rate was less than $50 \%$ in advanced cases $(6,8)$. Therefore, development of novel therapies are needed.

Chemical drugs are known to not only have direct killing effects on cancer cells but also to sensitize the target cells to cytotoxic T-lymphocytes (CTL) and favorably modulate the immune system (11-14). For example, it has been shown that 5-FU upregulates the expression of tumor antigens, HLA-class I molecules, or FAS, on the surface of target cells such as cell lines derived from breast carcinoma (15), colon carcinoma $(16,17)$, melanoma (18) and oral squamous cell 
carcinoma (OSCC) (19), which results in enhancement of the killing activity by tumor antigen-specific CTL toward these tumor cells. The platinum-based drugs cisplatin, carboplatin, and oxaliplatin enhance engulfment of the apoptotic tumor cells by dendritic cells (DCs) through calreticulin exposed on the plasma membrane of the apoptotic tumor cells (20), and ATP released from dying tumor cells promotes chemoattractive recruitment of DCs to tumor sites (21), and activation and crosspresentation of DCs by recognition of high-mobility group protein box-1 (HMGB-1) with toll like receptor 4 (TLR4) on the DCs (22). Moreover, it has been demonstrated that paclitaxel, cisplatin, and doxorubicin enhance tumor cell susceptibility to CTL-mediated killing, which is mediated via upregulation of mannose-6-phosphate receptors on the surface of tumor cells (23). Furthermore, several drugs have been reported to cause a reduction of immunosuppressive cells such as regulatory T-cells (Tregs), M2 macrophages and myeloidderived suppressive cells (MDSCs) (14). Therefore, it is likely that continuous immune responses, induced by chemotherapy, to cancer are related to long durable responses. Thus, the development of combined therapies with chemical drugs and immunotherapies for many types of advanced cancers have become recent, challenging issues (24).

In our hospital, adoptive immunotherapy using T-cells activated by autologous cancer tissue has been conducted in the past decade for several types of advanced cancers, including $\mathrm{HNC}$, and has shown objective responses in 3 of 10 patients with $\mathrm{HNC}$, including 2 complete remissions (25). Based on these studies, we are attempting to obtain basic research data that can be utilized in development of combined immunotherapy with T-cell infusion and chemical drugs in advanced HNC, especially in CDDP-resistant cases and in physically weak patients who cannot withstand strong drug side effects. We investigated in this study the influence of FP treatment on T-cell functions such as proliferation, cytokine release response and cytotoxicity in vitro using cytomegalovirus (CMV) pp65 antigen-specific cytotoxic T-lymphocytes (CMVpp65-CTLs). The main reason why we used CMVpp65CTLs instead of tumor specific-CTLs is that it is very difficult to prepare enough tumor specific-CTLs for study. However, it is reliable to use CMVpp65-CTLs in an in vitro model like the one in this study because it is easy to prepare enough CMVpp65-CTLs in one batch, and, in general, the molecular mechanisms involved in killing target cells by the virus-CTLs, including CMVpp65-CTLs, are the same as those used by tumor specific-CTLs (26-28).

\section{Materials and methods}

Antibodies, MHC-tetramers and flow cytometry. PerCPconjugated anti-CD8 monoclonal antibody (mAb) was purchased from eBioscience Inc. (San Diego, CA, USA). Allophycocyanin (APC)-conjugated HLA-A*24:02 CMV pp65 tetramer-QYDPVAALF, APC-conjugated HLA-A*02:01 CMV pp65 tetramer-NLVPMVATV, FITC-conjugated anti-HLAA2 $\mathrm{mAb}$ and FITC-conjugated anti HLA-A24 mAb were purchased from MBL Co. (Nagoya, Japan). For intracellular IFN- $\gamma$ staining, the induced CMVpp65-CTLs were co-cultured with or without the cognate CMVpp65 synthetic peptides at $37^{\circ} \mathrm{C}$ in $5 \% \mathrm{CO}_{2}$ for $2 \mathrm{~h}$ in the presence of $1 \mu \mathrm{g} / \mathrm{ml}$ brefeldin $\mathrm{A}$
(BD Biosciences, San Jose, CA, USA). Subsequently, they were fixed in $10 \%$ formaldehyde and stained with FITC-conjugated anti-IFN- $\gamma$ mAb (45.15; Beckman Coulter, Fullerton, CA, USA) with $0.25 \%$ saponin for $30 \mathrm{~min}$ at room temperature. CMVpp65 antigen was detected by anti-CMVpp65 mAb (Virusys, Inc., Taneytown, MD, USA). The cells were fixed with $10 \%$ formaldehyde for $30 \mathrm{~min}$ at $4^{\circ} \mathrm{C}$, and were washed 2 times. The cells were reacted with $5 \mu \mathrm{g} / \mathrm{ml}$ of mouse antiCMVpp65 mAb (Virusys, Inc.) including $0.25 \%$ saponin, and were subsequently reacted with FITC-conjugated anti-mouse IgG (MBL Co.). Cells were analyzed on a FACSCanto II (BD Biosciences) with the aid of Flow Jo software (Tree Star, Inc., Ashland, OR, USA).

Reagents. CDDP (Randa) was obtained from Nippon Kayaku Co., Ltd. (Tokyo, Japan). 5-FU was obtained from Kyowa Hakko Kirin Co., Ltd. (Tokyo, Japan). Premix WST-1 Cell Proliferation Assay System was purchased from Takara Bio Inc. (Otsu, Japan).

Cells and culture media. Peripheral blood mononuclear cells (PBMCs) were isolated by centrifugation on a Ficoll density gradient. Blood samples were collected after obtaining written informed consent, and the study was approved by the Institutional Review Board of Aichi Medical University. Primary T-cell lines were induced in RPMI-1640 (SigmaAldrich, St. Louis, MO, USA) supplemented with $25 \mathrm{mM}$ HEPES, $10 \%$ autologous plasma, gentacine, and $2 \mathrm{mM}$ L-glutamine (referred to as T-cell medium). Epstein-Barr virustransformed B cells (B-LCL) were established by infecting an aliquot of PBMCs with B95-8 supernatant. Human OSCC cell lines (HSC-2, HSC-3, and HSC-4) were obtained from the Japanese Collection of Research Bioresource Cell Bank. Cells were maintained in DMEM (Gibco, Paisley, UK) supplemented with $10 \%$ fetal bovine serum (FBS) (HyClone Laboratories, Inc. South Logan, UT, USA) and $1 \%$ penicillin-streptomycin (Gibco, Grand Island, NY, USA) at $37^{\circ} \mathrm{C}$ in $5 \% \mathrm{CO}_{2}$ humidified air. Adherent cells were dissociated from a $25 \mathrm{~cm}^{2}$ flask by using trypsin and seeded in 96-well plates for the experiments.

Preparation of CMVpp65-CTLs. CMVpp65-CTLs were prepared by mixed lymphocyte peptide cultures (MLPCs) followed by the CD137-guided CTL isolation method (29). MLPCs were performed as follows: $0.1 \mu \mathrm{M}$ HLA-A*24:02- or HLA-A*02:01-restricted synthetic CMV pp65 T-cell epitope peptides [QYDPVAALF aa 341-349 (30) or NLVPMVATV aa 495-503 (31)], respectively, (MBL Co.) were directly added to PBMCs suspended in $1 \mathrm{ml} \mathrm{T}$ lymphocyte medium at a cell concentration of $2.0 \times 10^{6} / \mathrm{ml}$, and the cultures were maintained in $15 \mathrm{ml}$ round bottom tubes at $37^{\circ} \mathrm{C}$ and $5 \% \mathrm{CO}_{2}$ for 2 days. On day 2, $1 \mathrm{ml}$ of $\mathrm{T}$ lymphocyte medium supplemented with $100 \mathrm{IU} / \mathrm{ml}$ of IL-2 was added. Starting on day 7, half of the medium supernatant was removed and an equal volume of ALyS505N medium (Cell Science \& Technology Institute, Inc., Sendai, Japan) supplemented with 100 IU/ml of IL-2 was added. Until day 14, the cells were cultured with appropriate medium (ALyS505N with $100 \mathrm{IU} / \mathrm{ml}$ of IL-2). Then, a CD137-guided CTL isolation was performed. CMV-CTLs prepared by MLPCs were re-stimulated for 2 days by the cognate peptide-pulsed autologous B-LCLs, and isolated by 


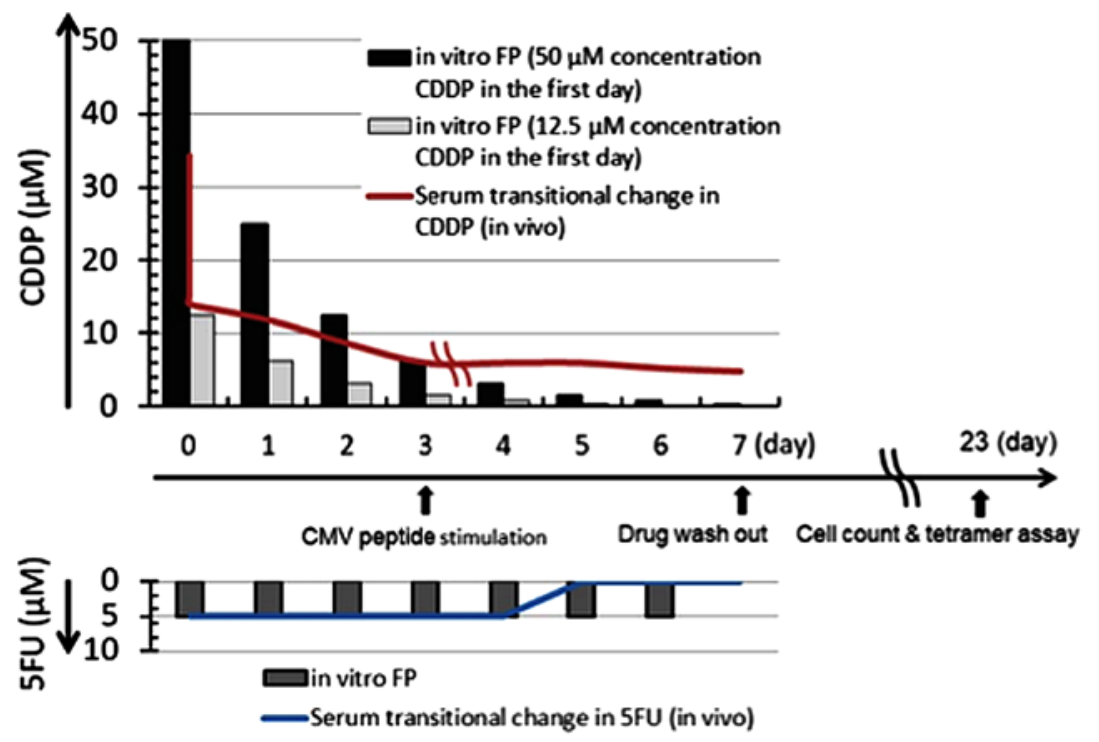

Figure 1. Comparison of the transitional changes in the drug concentration in the plasma of a patient undergoing FP treatment with those in the cell culture during FP treatment. The red line was traced from kinetics data in the interview form of RANDA. Black bars and light gray bars indicate the CDDP concentrations in the culture during in FP treatment. The bold blue line indicates the 5-FU concentration in the plasma of the FP-treated patient, and the dark gray bars indicate the 5-FU concentration in the culture during FP treatment.

the anti-human CD137 MicroBeads kit (Miltenyi Biotec Inc., Bergisch Gladbach, Germany). The isolated cells were propagated for 7 days in ALyS505N medium supplemented with $100 \mathrm{IU} / \mathrm{ml}$ of IL-2. Cultures were fed by changing half of the supernatant twice a week. Viable cell counts were determined using the trypan blue assay.

Effect of FP treatment on CMVpp65-CTL induction. PBMC from a healthy volunteer who was HLA-A*24:02 positive were suspended in T-cell medium at a cell concentration of $10 \% \mathrm{ml}$, and $1 \mathrm{ml}$ cell suspensions were dispensed into $15 \mathrm{ml}$ roundbottom tubes in duplicate, and CDDP and 5-FU were added to each of the duplicate tubes at final concentrations of $12.5 \mu \mathrm{M}$ or $50 \mu \mathrm{M}$, respectively, for CDDP and $5 \mu \mathrm{M}$ for $5-\mathrm{FU}$, and the cells were cultured at $37^{\circ} \mathrm{C}$ in $5 \% \mathrm{CO}_{2}$. CDDP concentrations were reduced by half every day until day 5 , while the $5-\mathrm{FU}$ concentration was maintained at $5 \mu \mathrm{M}$, in order to simulate the changing drug concentration in the plasma of patients during FP treatment (Fig. 1). On day 7, the drugs were washed out by washing the cells 3 times. HLA-A*24:02-restricted CMVpp65 T-cell epitope peptide QYDPVAALF (MBL Co.) was added on day 3 at a final concentration of $0.1 \mu \mathrm{M}$, and 2 days after addition of the peptide, IL-2 was added at a final concentration of $50 \mathrm{IU} / \mathrm{ml}$, and the cells were cultured for 5 days. Then, half of the medium supernatants were removed and equal volumes of ALyS505N medium (Cell Science \& Technology Institute, Inc.) supplemented with $100 \mathrm{IU} / \mathrm{ml}$ of IL-2 were added. The cells were cultured until day 23 in the appropriate medium (ALyS505N with $100 \mathrm{IU} / \mathrm{ml}$ of IL-2). Viable cell counts were determined using the trypan blue assay.

Construction of CMVpp65 antigen-expressing lenti-viral vector and infection. Lentiviral vectors encoding full-length human CMVpp65 antigen fused with the fluorescent protein, Tomato, in the c-terminus (pLVSIN-CMV Neo_pp65-TMT), and the MOCK vector encoding Tomato (pLVSIN-CMV
Neo_TMT) were constructed by recombination of each of the synthesized cDNAs with the lentiviral vector, pLVSIN-CMV Neo (Takara Bio Inc.). pLVSIN-CMV Neo_pp65-TMT or pLVSIN-CMV Neo_TM) were co-transfected with Lentiviral High Titer Packaging Mix (Takara Bio Inc.) into 293T/17 cells (ATCC, Manassas, VA, USA). Forty-eight hours after the co-transfection, the culture supernatant, including virus particles, was used for infection of OSCC cell lines with the lentivirus. The infected OSCC cells were cultured in DMEM supplemented with $250 \mu \mathrm{g} / \mathrm{ml}$ of G418, and the Tomatoexpressing cells were isolated by FACSAria III (Becton Dickinson). CMVpp65 expression by the infected cells was analyzed by flow cytometry using anti-CMVpp65 mAb.

Establishment of CDDP-resistant subline from the HSC-3. A CDDP-resistant subline was raised over 3 months by continuous exposure to $1.25 \mu \mathrm{M}$ concentration of CDDP, and cultured in DMEM medium. Subsequently, the CDDP resistance of the surviving cells was increased over 3 months by continuous exposure to $2.5 \mu \mathrm{M}$ concentration of CDDP. The resistant subline was then considered established and was named HSC-3/CDDP-R1.

Drug sensitivity and sensitivity to CTL-mediated killing of OSCC cell lines. Two days after OSCC cells were seeded in 96-well plates at 20,000 cells per well, serial concentrations of drugs and serial numbers of CMVpp65-CTLs were added in triplicate and cultured for 4-7 days. Then, each well was washed with $150 \mu$ l of PBS 3 times to remove the dead cells and the CTL cells, and the cell viability assay was performed by incubating with WST-1, a highly water-soluble disulfonated tetrazolium salt, 4-[3-(2-methoxy-4-nitrophenyl)2-(4-nitrophenyl)-2H-5-tetra-zolio]-1,3-benzene disulfonate sodium salt (32). The absorbance (OD) was measured with a micro-plate reader (SpectraMAX M5 spectrophotometer, Molecular Devices, Sunnyvale, CA, USA) at a wavelength 

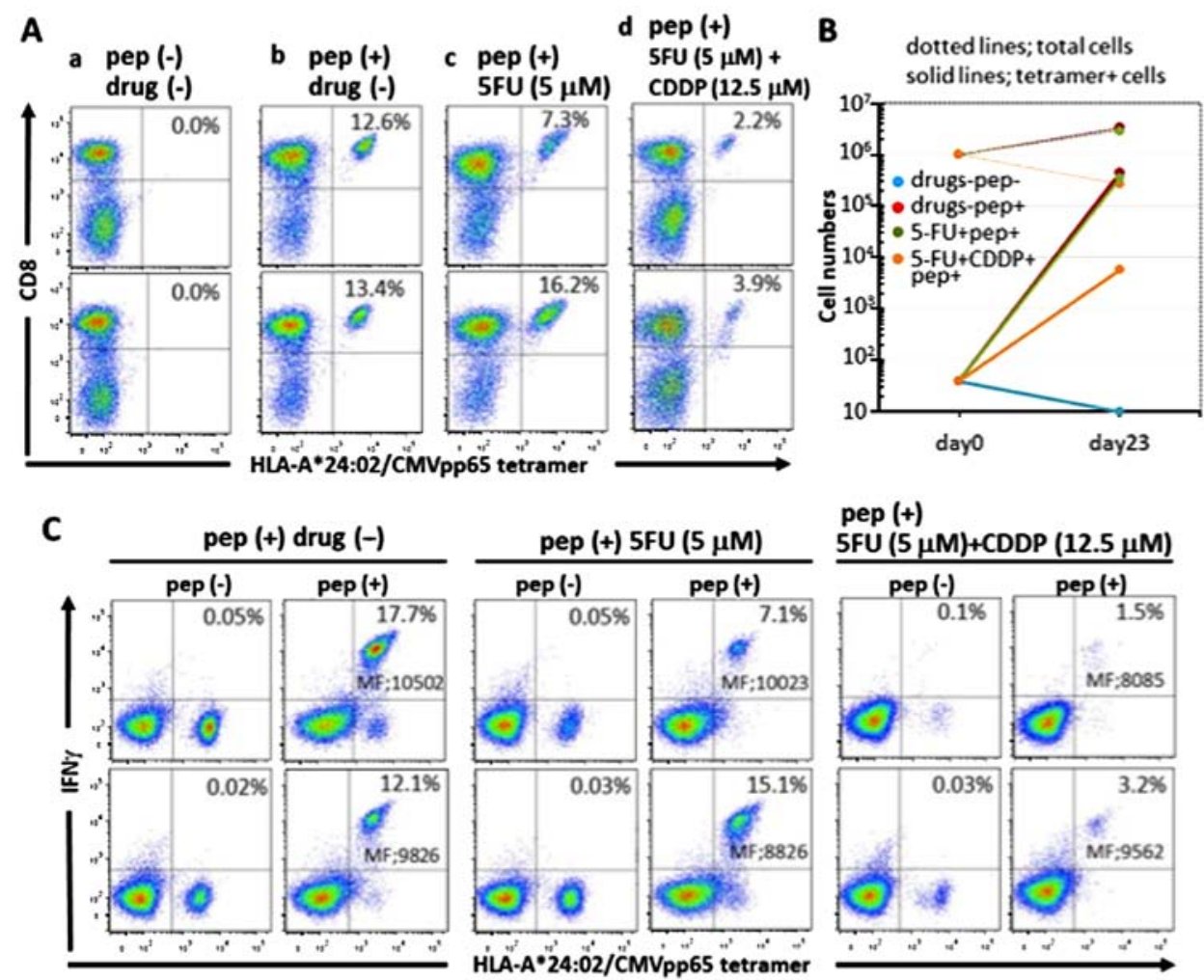

pep (+) SFU $(5 \mu \mathrm{M})+\operatorname{CDDP}(12.5 \mu \mathrm{M})$

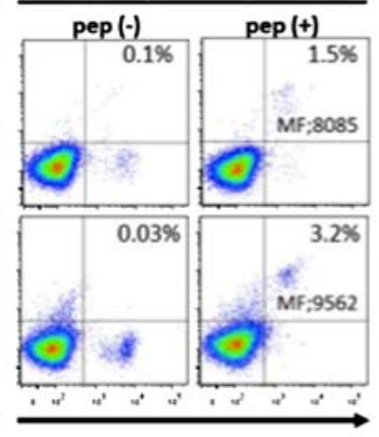

Figure 2. Induction of CMVpp65-CTLs in the presence of the drugs. (A) HLA-A*24:02-restricted CMVpp65-CTLs were induced in duplicate from PBMC of a healthy donor by culturing for 23 days under different conditions: incubation in the absence of the drugs and the peptide (a), incubation in the presence of the epitope peptide only (b), incubation with $5 \mu \mathrm{M} 5$-FU and the epitope peptide (c) and incubation with $5 \mu \mathrm{M} 5$-FU+12.5 $\mu \mathrm{M}$ CDDP and the epitope peptide (d). The cells were stained for CMVpp65 tetramer and CD8 and analyzed by flow cytometry. The viable cell population was determined by FSC and SSC levels, and the data are plotted to show CD8 and HLA-A*24:02 CMVpp65 tetramer-positivity. Percentages relative to the entire viable cell population of both CD8 and HLA-A*24:02 CMVpp65 tetramer-positive cells are indicated in each panel. (B) Expansion of the total cell numbers and the tetramer-positive CMVpp65-CTL cell numbers: the total cell numbers and the tetramer-positive CMVpp65-CTL cell numbers on day 0 and 23, respectively, were plotted. HLA-A*24:02-restricted CMVpp65-CTLs were induced in duplicate as described below. Solid lines and dotted lines indicate expansion of the total cells and the tetramer-positive cells, respectively. Each color signifies the following: blue, no drugs and no peptide; red, epitope peptide only; green, $5 \mu \mathrm{M} 5$-FU and the epitope peptide; orange, $5 \mu \mathrm{M}$ 5-FU+12.5 $\mu \mathrm{M}$ CDDP and the epitope peptide. (C) Intracellular IFN- $\gamma$ assay of the induced CMVpp65-CTLs: the induced CTLs under different conditions as described in (A): incubation in the presence of the epitope peptide only (a), incubation with $5 \mu \mathrm{M} 5$-FU and the epitope peptide (b) and incubation with $5 \mu \mathrm{M} 5$-FU+12.5 $\mu \mathrm{M}$ CDDP and the epitope peptide (c), were cultured with the cognate peptide [pep (+)] or no peptide [pep (-)] in the presence of brefeldin A for $2 \mathrm{~h}$, and stained with HLA-A*24:02 CMVpp65 tetramer and anti-IFN- $\gamma \mathrm{mAb}$ and analyzed by flow cytometry. Percentages relative to the entire viable cell population of both IFN- $\gamma$ and HLA-A $24: 02$ CMVpp65 tetramer-positive cells are indicated in each panel. MF in the panels indicates mean fluorescence intensity of IFN- $\gamma$ and HLA-A*24:02 CMVpp65 tetramer-positive cells.

of $450 \mathrm{~nm}$. Cell viability was calculated according to the following formula: $\%$ viability $=100 \times(E-S) /(M-S)$, where $\mathrm{E}$ is the absorbance of experimental well, $\mathrm{M}$ is the absorbance in the absence of CTL and/or drugs (cells were incubated with medium alone), and $\mathrm{S}$ is that of medium alone. An average of triplicate measurements is shown.

\section{Results}

Effect of FP treatment on CTL induction. The CMVpp65 tetramer positivity in each well of duplicate cultures of PBMC stimulated with the epitope peptide in the absence of the drugs on day 23 was increased to 12.6 and $13.4 \%$, respectively, from $0.004 \%$ on day 0 , whereas the cultures stimulated with 5-FU $(5 \mu \mathrm{M})$ were 7.3 and $16.2 \%$, respectively. The cultures stimulated with FP treatment [5-FU $(5 \mu \mathrm{M})+\mathrm{CDDP}$ $(12.5 \mu \mathrm{M})$ ] were 2.2 and $3.9 \%$, respectively (average, 3.05\%) (Fig. 2A). Since the numbers of cells were extremely reduced, cultures treated with FP at a high concentration of CDDP [5-FU $(5 \mu \mathrm{M})+\mathrm{CDDP}(50 \mu \mathrm{M})]$ could not be measured. The total cell numbers and tetramer-positive cell numbers in each well of duplicate culture of PBMC stimulated with the epitope peptide on day 23 in the absence of the drugs were increased to $28.5 \times 10^{5}$ and $37.8 \times 10^{5}$ (growth rate; 3.32 -fold) and $35.9 \times 10^{4}$ and $50.7 \times 10^{4}$ (growth rate; 10,825 -fold), respectively, from $10.0 \times 10^{5}$ and $0.4 \times 10^{2}$ on day 0 , respectively. Cultures that were treated with a single treatment of 5-FU $(5 \mu \mathrm{M})$ were increased to $24.6 \times 10^{5}$ and $33.0 \times 10^{5}$ (growth rate; 2.28 -fold) and $1.8 \times 10^{5}$ and $5.3 \times 10^{5}$ (growth rate; 8,925-fold), respectively, and in cultures receiving FP treatment of 5-FU $[5 \mu \mathrm{M})+\operatorname{CDDP}(12.5 \mu \mathrm{M})]$, the total cell numbers in each well were increased to $2.5 \times 10^{5}$ and $3.0 \times 10^{5}$ (growth rate; 0.28 -fold), respectively, and the tetramer-positive cell numbers in each well were increased to $0.6 \times 10^{4}$ and $1.2 \times 10^{4}$ (growth rate; 215-fold), respectively (Fig. 2B). Summing up these observations, although the effect on CMVpp65-CTL induction in the 5-FU $(5 \mu \mathrm{M})$ single-treatment cultures was minimal, there was a partial effect in the FP-treated cultures that was especially remarkable at a high concentration of CDDP [5-FU $(5 \mu \mathrm{M})+\operatorname{CDDP}(50 \mu \mathrm{M})]$. 
A

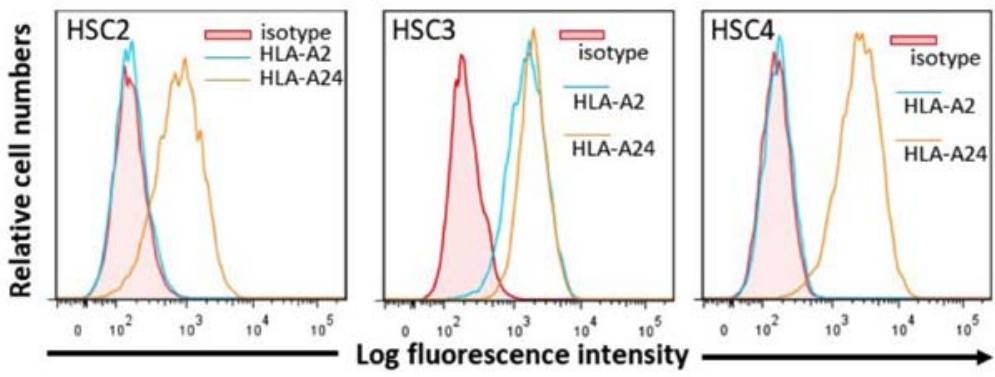

B

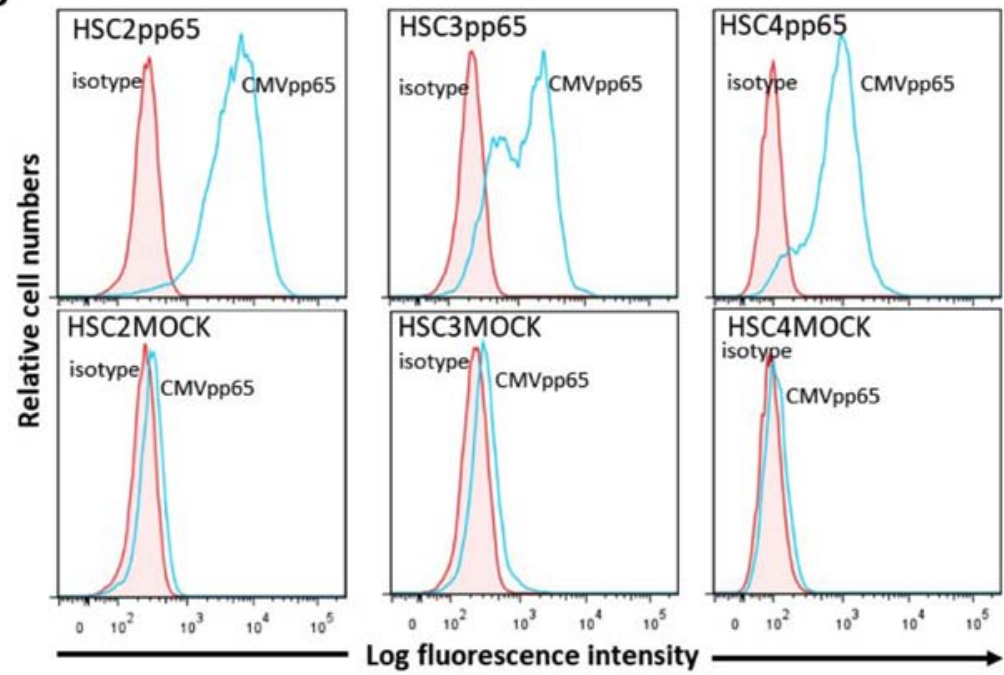

Figure 3. Flow cytometric analysis of expression of HLA molecules and CMVpp65 antigen in OSCC cells. (A) HLA expression in OSCC cell lines. The cells were stained with anti-HLA-A24 mAb (orange line histograms), anti-HLA-A2 mAb (blue line histograms) or isotype control mAb (red line filled histograms). (B) CMVpp65 expression in lentivirus-infected OSCC cell lines, The cells were stained with anti-CMVpp65 mAb (blue line histograms) or isotype control $\mathrm{mAb}$ (red line filled histograms).

The immune response of the induced CMVpp65-CTL in the presence of drugs to the cognate epitope peptide was evaluated by an intracellular IFN- $\gamma$ assay (Fig. $2 \mathrm{C}$ ). IFN- $\gamma$ production was preferentially shown in the tetramer-positive cells in every well, and the mean fluorescence intensity of IFN- $\gamma$ was almost equal between wells receiving non-treatment, 5-FU single-treatment and FP treatment. This observation indicates that the IFN- $\gamma$ production per cell was not inhibited by these drugs. Thus, these drug treatments did not affect the specific response of CMVpp65-CTL.

Expression of HLA class I molecules and CMVpp65 antigen in OSCC cells. Flow cytometric analysis showed that HLA-A24 was expressed on all of the OSCC cells, HSC-2, HSC-3 and HSC-4, that were used in this study; and HLA-A2 was expressed on HSC-3, but not on HSC-2 and HSC-4. CMVpp65 was specifically expressed in CMVpp65-transfected OSCC cells but not in the MOCK cells (Fig. 3).

Preparation of CMV-CTLs. We successfully prepared highly purified HLA-A24-restricted CMV-CTLs (A24-CMV-CTLs) from donor 1 and HLA-A2-restricted CMV-CTLs (A2-CMVCTLs) from donor 2 with 90.2 and $97.1 \%$ MHC-tetramer positivity, respectively. These CMV-CTLs showed specific full cytotoxic activity toward pp65-expressing OSCC cells in an HLA-type-restricted manner. The cytotoxicity was shown even at a very low E/T ratio (1/128) (Fig. 4).
Effect of 5-FU and/or CDDP on cytotoxicity of CMVpp65CTLs toward OSCC cells. HLA subtypes are different between these cell lines. HSC- 3 is HLA-A $24^{+} /$HLA-A $2^{+}$, HSC- 2 and HSC-4 are HLA-A $24^{+} /$HLA-A2-. Synergistic effects of 5-FU and/or CDDP to antigen-specific cytotoxicity of CTL in a HLA-subtype-restricted manner can be exactly investigated by using target cell lines that have different HLA subtypes.

The sensitivity of OSCC cells to CMVpp65-CTL was measured at serial $\mathrm{E} / \mathrm{T}$ ratios in combination with serial concentrations of 5-FU and/or CDDP in order to evaluate the effect of 5-FU and/or CDDP on the cytotoxicity of CMVpp65CTLs using the WST-1 assay. When CMVpp65-CTLs were co-cultured with the HLA-type-matched CMVpp65expressing OSCC cells, a remarkable reduction of the cell viability was observed in an $\mathrm{E} / \mathrm{T}$ ratio-dependent manner at all drug concentrations (panels a, b and $\mathrm{c}$ in Figs. 5A and 6A, panels $\mathrm{b}$ in Figs. 5B and 6B), and the ' $\mathrm{E} / \mathrm{T}$ 50' (E/T ratio indicating $50 \%$ cell viability) was shifted to a low ratio in a drug concentration-dependent manner (panels $b$ and $c$ in Fig. 5A; panels a, b and $\mathrm{c}$ in Fig. 6A; panel b in Figs. 5B and $6 \mathrm{~B})$. Conversely, a remarkable reduction of the cell viability was also observed in a drug concentration-dependent manner at all $\mathrm{E} / \mathrm{T}$ ratios, and the $\mathrm{IC}_{50}$ of these drugs was shifted to a low value in an $\mathrm{E} / \mathrm{T}$ ratio-dependent manner (panels $\mathrm{a}, \mathrm{b}$ and $\mathrm{c}$ in Fig. 7, panels a and b in Fig. 8). These results indicate that neither 5-FU nor CDDP affected the cytotoxicity of CTL, but that CTL treatment in combination with 5-FU and/or CDDP 
A

HLA-A•24:02-restricted CMVpp65-CTLs
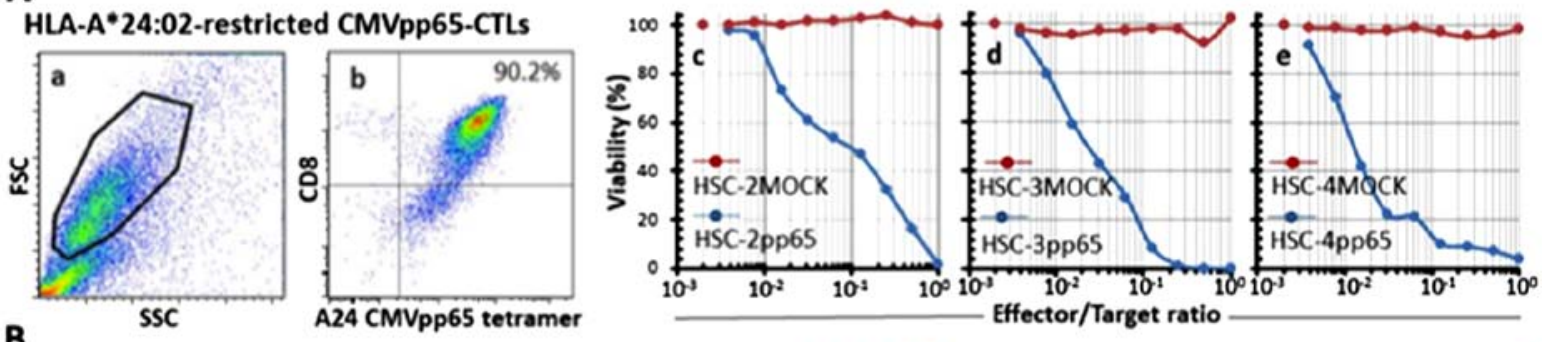

HLA-A*02:01-restricted CMVpp65-CTLs
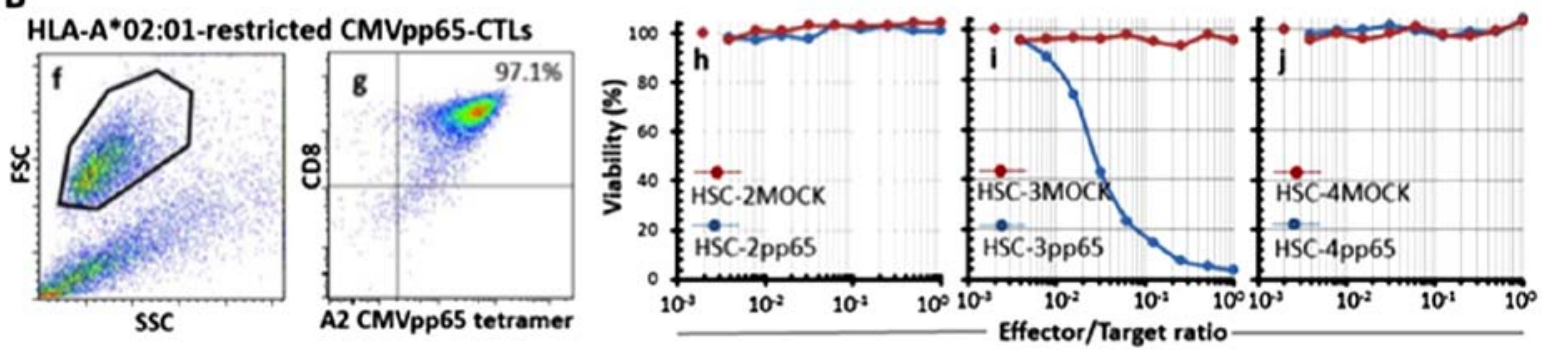

Figure 4. Purity and specificity of the prepared CMVpp65-CTLs. HLA-A*24:02-restricted CMVpp65-CTLs (A) and HLA-A*02:01-restricted CMVpp65CTLs (B) were prepared from an HLA-A24-positive healthy donor and an HLA-A2-positive healthy donor, respectively, and were evaluated for purity and specificity. The cells were stained for CMVpp65 tetramer and CD8 and analyzed by flow cytometry. The viable cell population was determined by FSC and SSC levels (a and f, respectively) and the data are plotted to show CD8 and HLA-A*24:02 or HLA-A*02:01/CMVpp65 tetramer-positivity (b and g, respectively). Percentages relative to the entire viable cell population of both CD8 and HLA-A*24:02 or HLA-A*02:01/CMVpp65 tetramer-positive cells are indicated in each panel. The cytotoxicity of the CMVpp65-CTLs were indirectly evaluated by the WST-1 assay. HLA-A*24:02-restricted CMVpp65-CTLs or HLA-A*02:01-restricted CMVpp65-CTLs were co-cultured with lentivirus-infected OSCC cell lines as the target cells for 7 days. When the target cells were co-cultured with HLA-A*24:02-restricted CMVpp65-CTLs, the viability of HSC-2pp65, HSC-3pp65 or HSC-4pp65 (blue lines in c-e, respectively) were reduced in an E/T ratio-dependent manner, but the viability of HSC-2MOCK, HSC-3MOCK or HSC-4MOCK (red lines in c-e, respectively) were not reduced. In contrast, when the target cells were co-cultured with HLA-A*02:01-restricted CMVpp65-CTLs, the viability of HSC-3pp65 but not HSC-2pp65 and HSC-4pp65 (blue lines in h-j, respectively) were reduced in an E/T ratio-dependent manner, but the viability of HSC-2MOCK, HSC-3MOCK or HSC-4MOCK (red lines in $\mathrm{h}-\mathrm{j}$, respectively) were not reduced. Each of the plots at the left side of the images that are not associated with a line shows the E/T ratio of 0.

generated a synergistic killing effect. Especially, 5-FU clearly sensitized HSC-3pp65 and HSC-4pp65 to CTL cytotoxicity. The cell viability was drastically reduced by CTLpp65-CTL cytotoxicity even at a low $\mathrm{E} / \mathrm{T}$ ratio in combination with 5-FU (panels $b$ and $c$ in Fig. 5A; panel b in Fig. 5B).

It is of interest to note that a slight reduction in cell viability was shown in an E/T ratio-dependent manner when MOCK OSCC cells, which do not express CMVpp65 antigen, were co-cultured with CMVpp65-CTLs in the presence of serial concentrations of the drugs. CMVpp65-CTLs did not reduce the cell viability without the presence of any drugs, even at a high E/T ratio (1/10). For example, when the HSC-3MOCK or HSC-4MOCK cells were co-cultured with CMVpp65CTLs, a significant reduction of cell viability was noted in an $\mathrm{E} / \mathrm{T}$ ratio-dependent manner in the presence of $2.5 \mu \mathrm{M}$ or $5.0 \mu \mathrm{M}$ of 5-FU, although CMVpp65-CTLs did not reduce the viability of HSC-3MOCK or HSC-4MOCK cells without the presence of any drugs (panels e and $\mathrm{f}$ in Fig. 5A and B). Moreover, HLA-A2-restricted CMVpp65-CTLs reduced the viability of both the HLA-type-mismatched HSC-4pp65 and HSC-4MOCK cells in an E/T ratio-dependent manner in the presence of 2.5 or $5.0 \mu \mathrm{M}$ of 5-FU, although the viability was not reduced without the presence of any drugs (panel $\mathrm{c}$ and $\mathrm{f}$ in Fig. 5B). These observations suggest that 5-FU sensitizes the HSC-3 and HSC-4 cells to the cytotoxicity of CMVpp65-CTLs in an antigen-non-specific as well as antigen-specific manner.

Susceptibility to 5-FU is different between these cell lines. HSC-2 cells were judged resistant to 5-FU because the cell viability was barely reduced even at a high 5 -FU concentration $(10.0 \mu \mathrm{M})$. The susceptibility of HSC-2 to 5 -FU is lower than those of HSC-3 and HSC-4, which may suggest one reason why the susceptibility of HSC-2 to CTL cytotoxicity is not enhanced by 5 -FU in comparison with HSC-3 and HSC-4. We suggest that 5-FU did not sensitize the 5-FU resistant cells to the cytotoxicity of CMVpp65-CTLs (panels a and d in Fig. 5A and B; panels a and d in Fig. 7A and B).

Cytotoxicity of CMVpp65-CTLs toward CDDP-resistant HSC-3 cells. The $\mathrm{IC}_{50}$ of CDDP to the parental HSC-3 and the CDDP-resistant HSC-3 cells, which were established in this study, were 5 and $20 \mu \mathrm{M}$, respectively, while the E/T50 of CMVpp65-CTLs toward the CMVpp65 T-cell epitope peptide-pulsed cells were both 1/10 (Fig. 9). Thus, it may be possible that the CTL treatment could also be effective in CDDP-resistant cases.

\section{Discussion}

Although chemoimmunotherapies are expected to improve the therapeutic effects of cancer treatment, the direct effect of chemical drugs on the functions of antigen-specific CTLs has not been clarified. Since most chemical drugs arrest the cell cycle, it is of concern that the immune responses of T-cells to tumor antigens may be inhibited during chemoimmunotherapy. We have studied the effects of FP treatment on the antigen-specific T-cell immune responses and functions using CMVpp65-CTLs in order to evaluate a potential immunotherapy in combination with FP treatment of HNC. CMVpp65-CTLs were used in this study because they are easier to handle in in vitro experiments than tumor-specific 
A

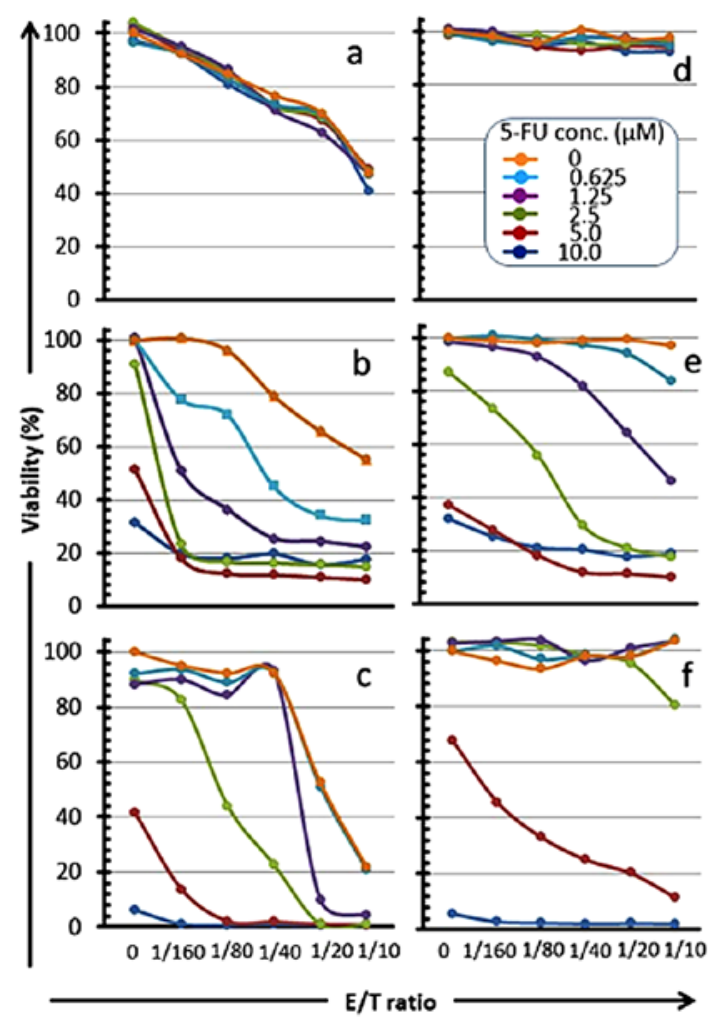

B

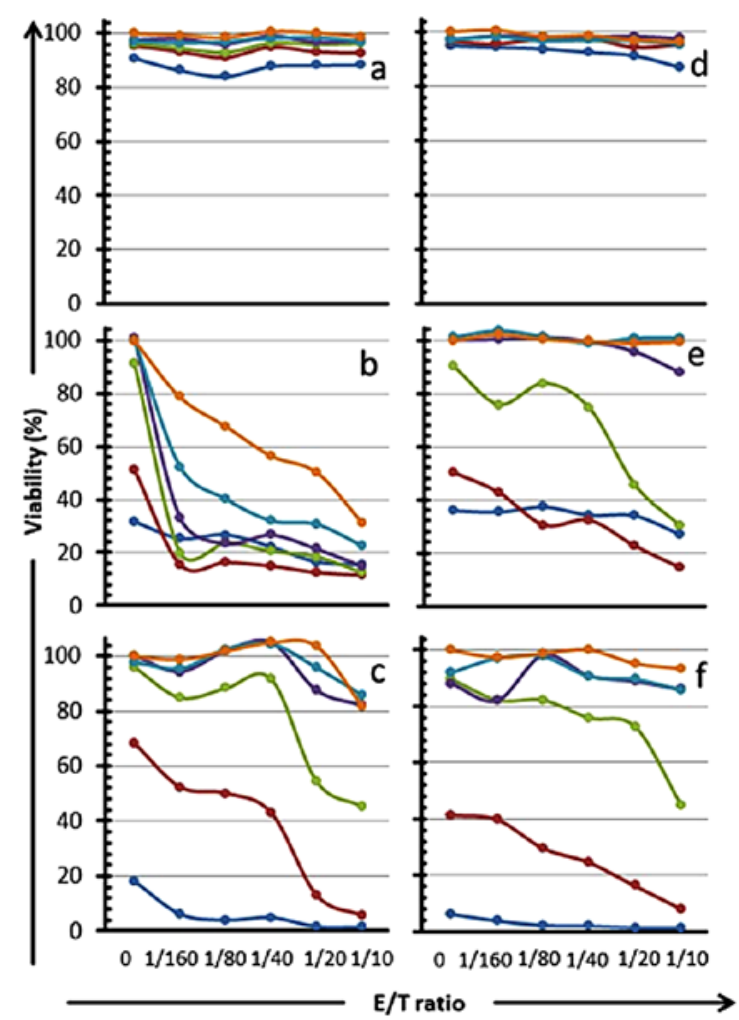

Figure 5. Reduction of OSCC cell viability by CMVpp65-CTLs in an E/T ratio-dependent manner in combination with 5-FU. CMVpp65-overexpressed OSCC cells (a, HSC-2pp65; b, HSC-3pp65; c, HSC-4pp65) or the MOCK cells (d, HSC-2MOCK; e, HSC-3MOCK; f, HSC-4MOCK) were co-cultured with HLA-A*24:02-restricted CMVpp65-CTLs (A) or HLA-A*02:01-restricted CMVpp65-CTLs (B) for 7 days in the presence of serial concentrations of 5-FU $(0,0.625,1.25,2.5,5,10 \mu \mathrm{M}$, as shown in A-d legend) and the viabilities of the target cells were measured by the WST-1 assay.

A



B

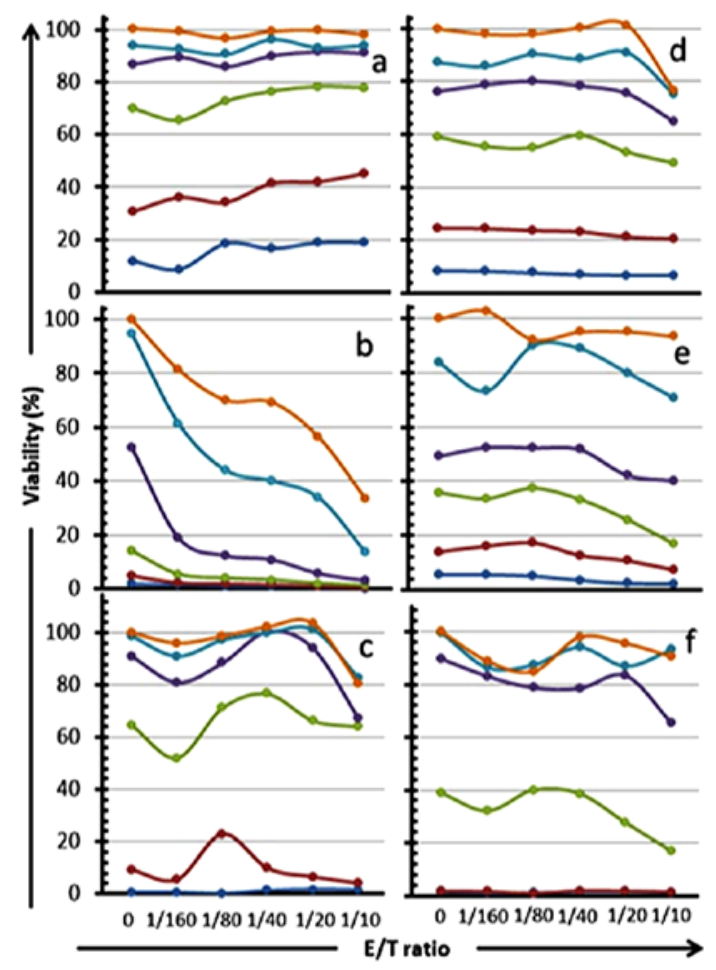

Figure 6. Reduction of OSCC cell viability by CMVpp65-CTLs in an E/T ratio-dependent manner in combination with CDDP. CMVpp65-overexpressed OSCC cells (a, HSC-2pp65; b, HSC-3pp65; c, HSC-4pp65) or the MOCK cells (d, HSC-2MOCK; e, HSC-3MOCK; f, HSC-4MOCK) were co-cultured with HLA-A*24:02-restricted CMVpp65-CTLs (A) or HLA-A*02:01-restricted CMVpp65-CTLs (B) for 7 days in the presence of serial concentrations of CDDP $(0,0.3125,0.625,1.25,2.5,5 \mu \mathrm{M}$, as shown in A-d legend) and the viabilities of the target cells were measured by the WST-1 assay. 
A

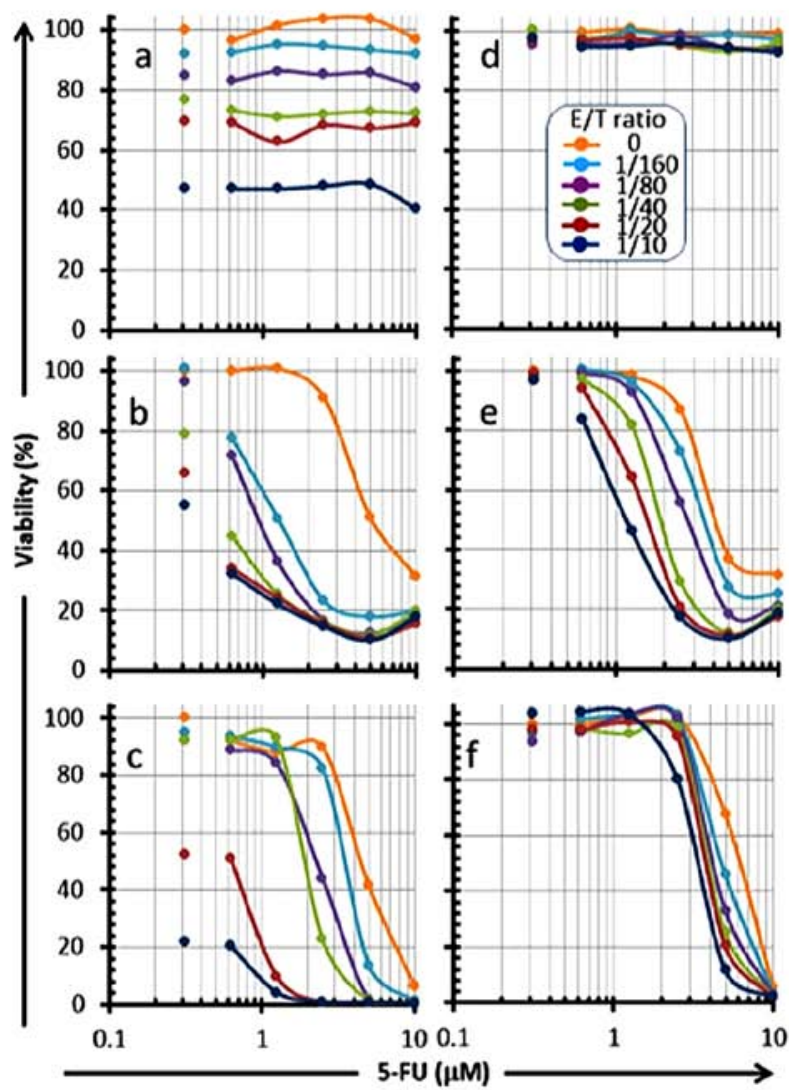

B

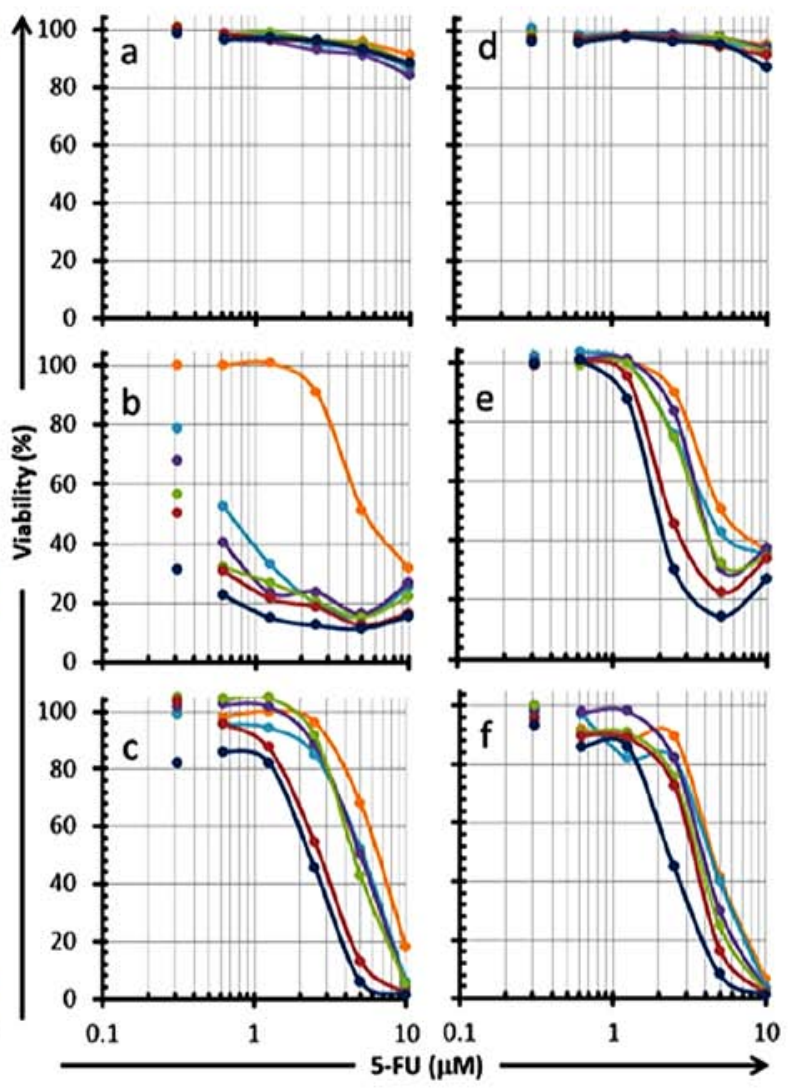

Figure 7. Reduction of OSCC cell viability in a 5-FU concentration-dependent manner in combination with serial E/T ratios of CMVpp65-CTLs. CMVpp65overexpressed OSCC cells (a, HSC-2pp65; b, HSC-3pp65; c, HSC-4pp65) or the MOCK cells (d, HSC-2MOCK; e, HSC-3MOCK; f, HSC-4MOCK) were co-cultured with 5-FU in the presence of serial E/T ratios (0, 1/160, 1/80, 1/40, 1/20, 1/10, as shown in A-d legend) of HLA-A*24:02-restricted CMVpp65-CTLs (A) or HLA-A*02:01-restricted CMVpp65-CTLs (B) for 7 days, and the viabilities of the target cells were measured by the WST-1 assay. Each of the left-side plots that are not associated with a line shows $0 \mu \mathrm{M}$ of $5-\mathrm{FU}$.

CTLs because, in general, the frequency of memory T-cells to CMVpp65 antigen in PBMC in healthy donors is very high (30). Moreover, CMVpp65-CTLs can be efficiently induced and proliferated by a simple technique using stimulation with CMVpp65 antigen T-cell epitope peptide. Therefore, antigen-specific T-cell responses and proliferation can be easily monitored in the culture by an intracellular IFN- $\gamma$ assay and an MHC-tetramer assay. Since a highly purified CMV-CTL line can be prepared by our CD137-guided isolation method (Fig. 4), antigen-specific cytotoxic activity can be evaluated exactly. In addition, although the affinity of the T-cell receptor for tumor antigen is considered to be lower than that for CMVpp65 antigen, the recognition and killing mechanisms of CMVpp65-CTLs are the same as those of tumor antigen-specific CTLs. Thus, an experimental study using CMVpp65-CTLs is very useful for evaluation of drug effects on $\mathrm{T}$-cell responses and functions.

First, the effects of CDDP and 5-FU on CMV-CTL induction were investigated in vitro in culture conditions in which the concentrations of the drugs were changed over time in order to simulate in vivo drug concentrations (Fig. 1). Inhibition of CMVpp65-CTL proliferation in vitro was limited in the presence of only 5-FU; in contrast, the proliferation was inhibited by the FP treatment, especially at a high concentration of CDDP (Fig. 2). However, the proliferation was not inhibited completely, and the IFN- $\gamma$ release response of the CMV-CTLs, which were induced in the presence of 5-FU and/or CDDP, was not inhibited at all. We suggest that 5-FU is adequate as a combination partner in immunotherapy, and that CDDP must be used at a low concentration when FP treatment is used in combination with immunotherapy, such as in a vaccine.

Second, we investigated the effects of 5-FU and CDDP on CMVpp65-CTL cytotoxicity using the CMVpp65 antigentransfected OSCC cell lines, HSC-2pp65, HSC-3pp65 and HSC-4pp65 as the targets. The drugs did not affect the cytotoxicity against any of the three target cells. It is important to note that a synergistic killing effect of CMVpp65-CTLs with 5-FU and/or CDDP was observed even at a very low $\mathrm{E} / \mathrm{T}$ ratio (less than 1/100). Especially, the $\mathrm{IC}_{50}$ value of 5-FU against HSC-3pp65 was drastically reduced in the presence of CMVpp65-CTLs even at the low E/T ratio of 1/160 (panels $b$ and $\mathrm{c}$ in Fig. 7A, panel $\mathrm{b}$ in Fig. 7B). Also noteworthy, a slight reduction of the $\mathrm{IC}_{50}$ of 5-FU against $\mathrm{HSC}-3 \mathrm{MOCK}$ was also observed in the presence of CMVpp65-CTLs (panels e and $\mathrm{f}$ in Fig. 7A and B). These observations were shown in both of the two CMVpp65-CTL lines used in this study. It is possible that 5-FU sensitized the target cells for CMVpp65-CTLs not only in an antigen-specific manner but also in a non-specific manner. It has been reported previously that CDDP and 5-FU have not only direct killing ability toward cancer cells but that they also can enhance the susceptibility of cancer cells to CTL by modulation of related molecules involved in apoptosis, sensitization to 
A

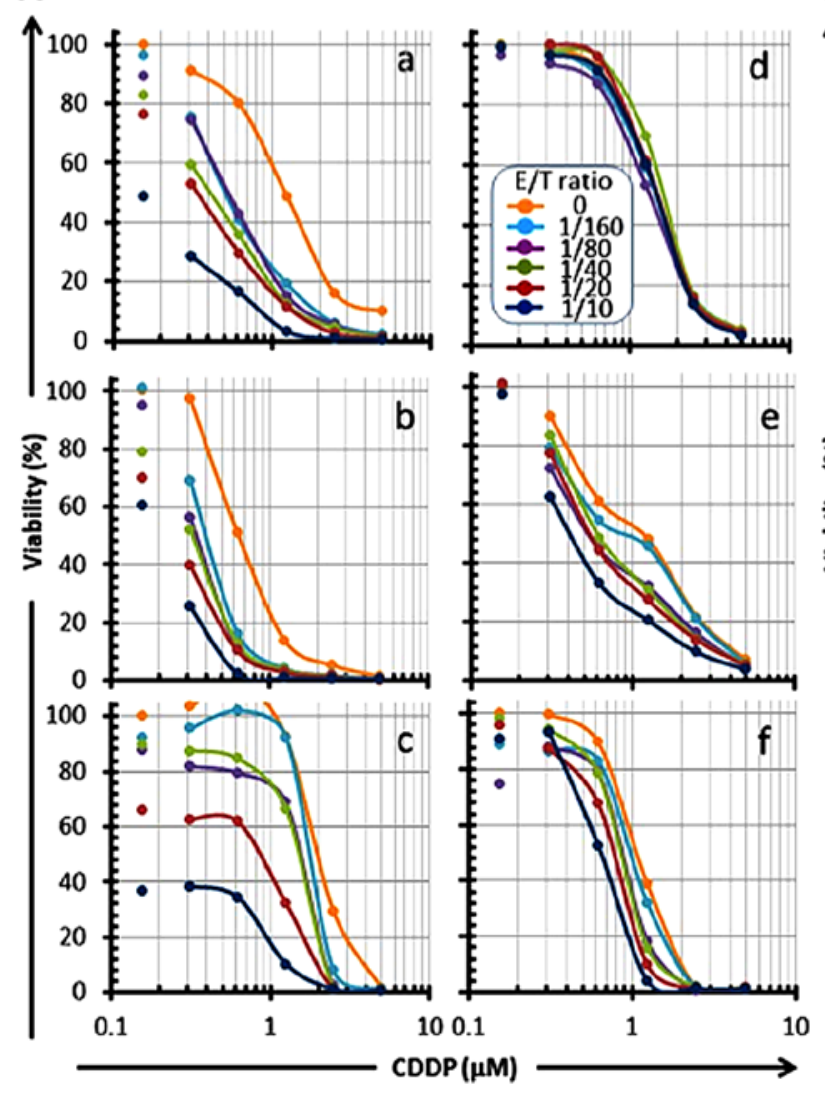

B

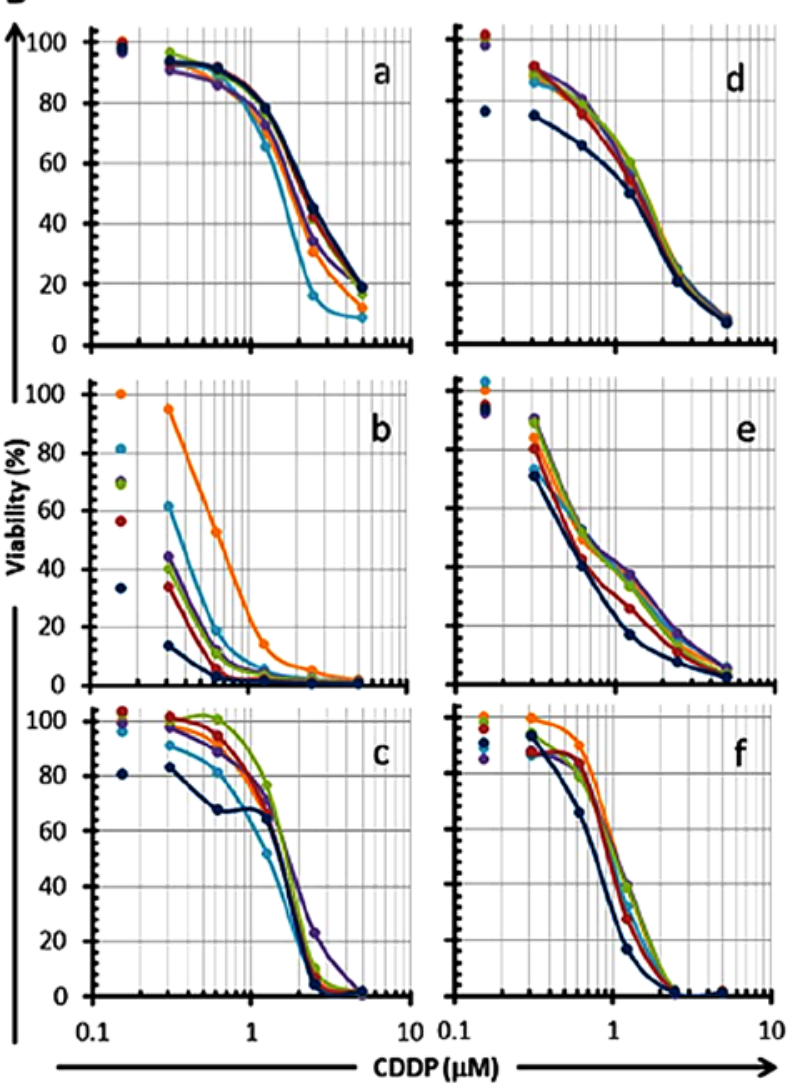

Figure 8. Reduction of OSCC cell viability by CMVpp65-CTLs in an E/T ratio-dependent manner in combination with CDDP. CMVpp65-overexpressed OSCC cells (a, HSC-2pp65; b, HSC-3pp65; c, HSC-4pp65) or the MOCK cells (d, HSC-2MOCK; e, HSC-3MOCK; f, HSC-4MOCK) were co-cultured with CDDP in the presence of serial E/T ratios (0, 1/160, 1/80, 1/40, 1/20, 1/10, as shown in A-d legend) of HLA-A*24:02-restricted CMVpp65-CTLs (A) or HLA-A*02:01-restricted CMVpp65-CTLs (B) for 7 days, and the viabilities of the target cells were measured by the WST-1 assay. Each of the left-side plots that are not associated with a line shows $0 \mu \mathrm{M}$ of CDDP.
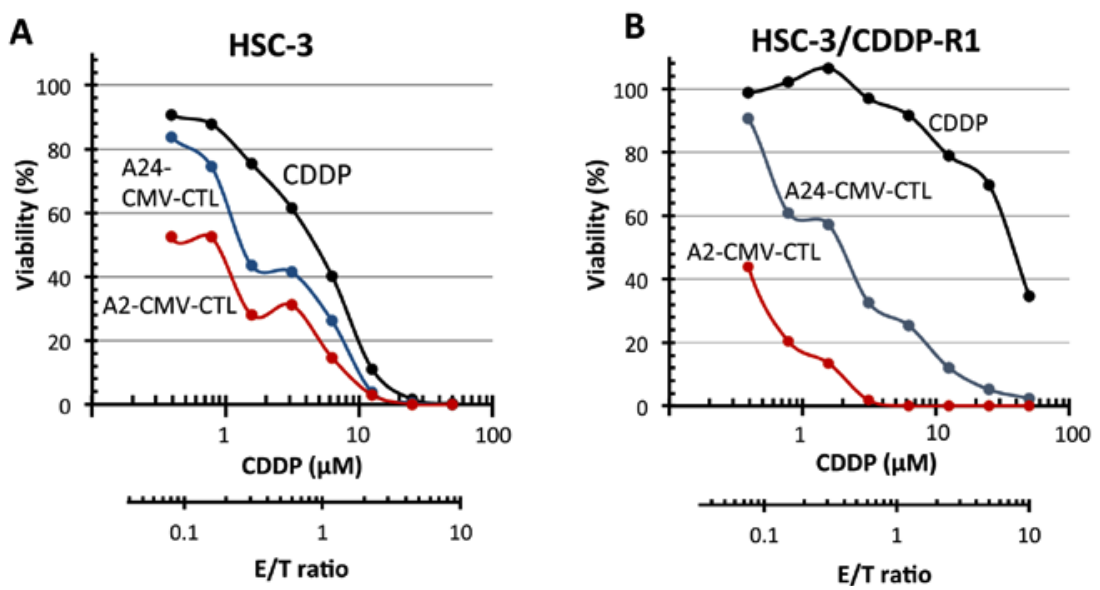

Figure 9. Sensitivity of HSC-3 and HSC-3/CDDP-R1 to CMVpp65-CTLs. CMVpp65 epitope peptide-pulsed HSC-3 (A) or HSC-3/CDDP (B) were cultured for 4 days in the presence of serial concentrations of CDDP (black line), serial E/T ratios of HLA-A*24:02-restricted CMVpp65-CTLs (blue line) or HLA-A*02:01-restricted CMVpp65-CTLs (red line), and the viabilities of the target cells were measured by the WST-1 assay.

CTLs, and activation of DCs. Although upregulation of tumor antigen, Fas and MHC class I expression have been suggested as potential mechanisms for target cell sensitization by 5-FU $(15,18)$, upregulation of such molecules was not observed in our experiments (data not shown). Other mechanisms are being considered as related to the sensitization. 5-FU did not sensitize HSC-2 which is indicated as being 5-FU-resistant (panel a in Figs. 5A and 7A). This observation suggests that molecules, related to the apoptosis-signaling cascade downstream of 5-FU are important for the sensitization. We are now planning to explore the molecules related to the sensitization in a protein array system.

Third, we tested the CMV-CTL killing activity toward CDDP-resistant HSC-3 cells in comparison with the activity 
toward the parental cells. Both of the CMVpp65-CTL lines showed a high killing activity toward CDDP-resistant HSC-3 cells that was the same as that toward parental HSC-3 cells (Fig. 9). Although CDDP has been clinically validated as being effective in a broad spectrum of cancers, the patients frequently acquire resistance and show heavy side effects. Therefore, combination therapy of CDDP with other cancer drugs has been applied as novel therapeutic strategies. Immunotherapy is considered to be an attractive combination with CDDP because the molecular mechanisms of action of CDDP (33) are different from the CTL killing mechanism (34), and the molecules related to CDDP resistance, such as membrane transporters, heat shock proteins, small GTPases, transcription factors, and DNA repair enzymes (35) do not affect the CTL killing activity. Our results suggest, therefore, a possible combination of immunotherapy with CDDP.

Several studies have been published on combinational vaccine therapy with CDDP and/or 5-FU. It was thus demonstrated that adenovirus encoding ovalbumin (Ad5-OVA) together with a low dose of 5-FU had a synergistic impact on survival in tumor-challenged mice. Enhancement of OVA-specific CTLs combined with elimination of tumor bulk were observed (36). It has also been demonstrated in mice that 5-FU combined with thymidine synthase (TS) peptide vaccine prevented the occurrence of tumors formed by inoculation of autologous $\left(\mathrm{TS}^{+}\right)$EL-4/HHD lymphoma cells (37). Our results may support these observations. In addition, in a clinical study, an increase was demonstrated in the immunological response in cases of personalized peptide vaccination combined with UFT and UZEL in metastatic colorectal cancer patients, and increases in immunological responses were also reported in advanced gastric or colorectal carcinoma patients receiving personalized peptide vaccine in combination with TS-1 (38,39). Furthermore, it was reported that a peptide vaccine in combination with 5-FU and CDDP, or with chemoradiation combined with 5-FU and CDDP effectively induced the peptide-specific CTLs $(40,41)$.

Collectively, our results and previous studies indicate that adoptive immunotherapy, conducted in our hospital using T-cells activated by autologous cancer tissue combined with FP treatment, might be possible by optimization of the CDDP concentration. This treatment is expected to have improved clinical effects, although FP treatment with a high dose of CDDP inhibited the induction of antigen-specific-CTLs. In addition, the treatment may be expected to be effective in patients with CDDP-resistant tumors and in those who cannot withstand the strong side effects by CDDP.

Recently, it has been shown that immune checkpoint systems and immunosuppressive cells, such as regulatory T-cells, M2 macrophages and MDSC, play important roles in creating immunosuppressive microenvironments in cancer, which result in tumor progression (24). The immune checkpoint inhibitors, ipilimumab (anti-CTLA4), nivolumab and pembrolizumab (anti-PD-1) have demonstrated excellent clinical effects beyond the conventional chemotherapy or molecular target therapy $(38,42,43)$. It has also been reported that depletion of Tregs by mogamulizumab (anti-CCR4) enhances cancer immune responses both in an in vitro study (44) and in a clinical study (45). Presently, modulation and regulation of immunosuppressive microenvironments in cancer have become major directions for development of cancer therapy. Since chemical drugs are effective not only in direct cytotoxicity but also in modulation of immune microenvironments in cancer, the development of combined therapies with chemical drugs and immunotherapies for many types of advanced cancers have become recent challenging issues. Adoptive immunotherapy developed in our hospital showed clinical effects with long-term survival even in stage IV patients with oral carcinomas, but $75 \%$ of the patients were non-responders (25). Immunosuppressive microenvironments in the cancer tissues might be considered as one of the reasons for poor responses. Development of comprehensive combined therapy with FP treatment, including immune checkpoint blockade and/or regulation of immunosuppressive cells, is considered to be necessary for improving the clinical effects of adoptive immunotherapy for HNC.

In conclusion, although the specific proliferation of CMVpp65-CTL by stimulation with CMVpp65 epitope peptide was partially affected by FP treatment, it was not affected by $5-\mathrm{FU}$, and the cytokine release response to CMVpp65 T-cell epitope peptide was not affected by FP treatment. Moreover, the cytotoxicity of CMVpp65-CTL toward OSCC cell lines overexpressing CMVpp65 antigen was not affected by CDDP and/or 5-FU, and it was identical toward CDDP-resistant cells and parent cells. These observations indicate that immunotherapy combined with FP treatment is effective in advanced HNC including CDDP-resistant cases and in physically weak patients who cannot withstand the strong side effects of CDDP.

\section{References}

1. Chaturvedi AK, Anderson WF, Lortet-Tieulent J, Curado MP, Ferlay J, Franceschi S, Rosenberg PS, Bray F and Gillison ML: Worldwide trends in incidence rates for oral cavity and oropharyngeal cancers. J Clin Oncol 31: 4550-4559, 2013.

2. Hori M, Matsuda T, Shibata A, Katanoda K, Sobue T and Nishimoto H; Japan Cancer Surveillance Research Group: Cancer incidence and incidence rates in Japan in 2009: A study of 32 population-based cancer registries for the Monitoring of Cancer Incidence in Japan (MCIJ) project. Jpn J Clin Oncol 45: 884-891, 2015.

3. Gibson MK, Li Y, Murphy B, Hussain MH, DeConti RC, Ensley $\mathbf{J}$ and Forastiere AA; Eastern Cooperative Oncology Group: Randomized phase III evaluation of cisplatin plus fluorouracil versus cisplatin plus paclitaxel in advanced head and neck cancer (E1395): An intergroup trial of the Eastern Cooperative Oncology Group. J Clin Oncol 23: 3562-3567, 2005.

4. Forastiere AA, Goepfert H, Maor M, Pajak TF, Weber R, Morrison W, Glisson B, Trotti A, Ridge JA, Chao C, et al: Concurrent chemotherapy and radiotherapy for organ preservation in advanced laryngeal cancer. N Engl J Med 349: 2091-2098, 2003.

5. Adelstein DJ, Li Y, Adams GL, Wagner H Jr, Kish JA, Ensley JF, Schuller DE and Forastiere AA: An intergroup phase III comparison of standard radiation therapy and two schedules of concurrent chemoradiotherapy in patients with unresectable squamous cell head and neck cancer. J Clin Oncol 21: 92-98, 2003.

6. Cooper JS, Pajak TF, Forastiere AA, Jacobs J, Campbell BH, Saxman SB, Kish JA, Kim HE, Cmelak AJ, Rotman M, et al; Radiation Therapy Oncology Group 9501/Intergroup: Postoperative concurrent radiotherapy and chemotherapy for high-risk squamous-cell carcinoma of the head and neck. NEngl J Med 350: 1937-1944, 2004.

7. Vermorken JB, Mesia R, Rivera F, Remenar E, Kawecki A, Rottey S, Erfan J, Zabolotnyy D, Kienzer HR, Cupissol D, et al: Platinum-based chemotherapy plus cetuximab in head and neck cancer. N Engl J Med 359: 1116-1127, 2008. 
8. Laramore GE, Scott CB, al-Sarraf M, Haselow RE, Ervin TJ, Wheeler R, Jacobs JR, Schuller DE, Gahbauer RA, Schwade JG, et al: Adjuvant chemotherapy for resectable squamous cell carcinomas of the head and neck: Report on Intergroup Study 0034. Int J Radiat Oncol Biol Phys 23: 705-713, 1992.

9. Bernier J, Domenge C, Ozsahin M, Matuszewska K, Lefèbvre JL, Greiner RH, Giralt J, Maingon P, Rolland F, Bolla M, et al European Organization for Research and Treatment of Cancer Trial 22931: Postoperative irradiation with or without concomitant chemotherapy for locally advanced head and neck cancer. N Engl J Med 350: 1945-1952, 2004.

10. Brockstein B, Haraf DJ, Rademaker AW, Kies MS, Stenson KM, Rosen F, Mittal BB, Pelzer H, Fung BB, Witt ME, et al: Patterns of failure, prognostic factors and survival in locoregionally advanced head and neck cancer treated with concomitant chemoradiotherapy: A 9-year, 337-patient, multi-institutional experience. Ann Oncol 15: 1179-1186, 2004.

11. de Biasi AR, Villena-Vargas J and Adusumilli PS: Cisplatininduced antitumor immunomodulation: A review of preclinical and clinical evidence. Clin Cancer Res 20: 5384-5391, 2014.

12. Hato SV, Khong A, de Vries IJ and Lesterhuis WJ: Molecular pathways: The immunogenic effects of platinum-based chemotherapeutics. Clin Cancer Res 20: 2831-2837, 2014.

13. Apetoh L, Ladoire S, Coukos G and Ghiringhelli F: Combining immunotherapy and anticancer agents: The right path to achieve cancer cure? Ann Oncol 26: 1813-1823, 2015.

14. Alizadeh D and Larmonier N: Chemotherapeutic targeting of cancer-induced immunosuppressive cells. Cancer Res 74 : 2663-2668, 2014.

15. Correale P, Aquino A, Giuliani A, Pellegrini M, Micheli L, Cusi MG, Nencini C, Petrioli R, Prete SP, De Vecchis L, et al: Treatment of colon and breast carcinoma cells with 5-fluorouracil enhances expression of carcinoembryonic antigen and susceptibility to HLA-A $(*) 02.01$ restricted, CEA-peptide-specific cytotoxic T cells in vitro. Int J Cancer 104: 437-445, 2003.

16. Correale P, Del Vecchio MT, Di Genova G, Savellini GG, La Placa M, Terrosi C, Vestri M, Urso R, Lemonnier F, Aquino A, et al: 5-fluorouracil-based chemotherapy enhances the antitumor activity of a thymidylate synthase-directed polyepitopic peptide vaccine. J Natl Cancer Inst 97: 1437-1445, 2005.

17. Bergmann-Leitner ES and Abrams SI: Treatment of human colon carcinoma cell lines with anti-neoplastic agents enhances their lytic sensitivity to antigen-specific CD8 ${ }^{+}$cytotoxic T lymphocytes. Cancer Immunol Immunother 50: 445-455, 2001.

18. Yang S and Haluska FG: Treatment of melanoma with 5-fluorouracil or dacarbazine in vitro sensitizes cells to antigen-specific CTL lysis through perforin/granzyme- and Fas-mediated pathways. J Immunol 172: 4599-4608, 2004.

19. Iwase M, Watanabe H, Kondo G, Ohashi M and Nagumo M: Enhanced susceptibility of oral squamous cell carcinoma cell lines to FAS-mediated apoptosis by cisplatin and 5-fluorouracil Int J Cancer 106: 619-625, 2003

20. Panaretakis T, Kepp O, Brockmeier U, Tesniere A, Bjorklund AC, Chapman DC, Durchschlag M, Joza N, Pierron G, van Endert P, et al: Mechanisms of pre-apoptotic calreticulin exposure in immunogenic cell death. EMBO J 28: 578-590, 2009.

21. Elliott MR, Chekeni FB, Trampont PC, Lazarowski ER, Kadl A, Walk SF, Park D, Woodson RI, Ostankovich M, Sharma P, et al: Nucleotides released by apoptotic cells act as a find-me signal to promote phagocytic clearance. Nature 461: 282-286, 2009.

22. Apetoh L, Ghiringhelli F, Tesniere A, Obeid M, Ortiz C, Criollo A, Mignot G, Maiuri MC, Ullrich E, Saulnier P, et al: Toll-like receptor 4-dependent contribution of the immune system to anticancer chemotherapy and radiotherapy. Nat Med 13: 1050-1059, 2007

23. Ramakrishnan R, Assudani D, Nagaraj S, Hunter T, Cho HI, Antonia S, Altiok S, Celis E and Gabrilovich DI: Chemotherapy enhances tumor cell susceptibility to CTL-mediated killing during cancer immunotherapy in mice. J Clin Invest 120 : $1111-1124,2010$

24. Suzuki S, Ishida T, Yoshikawa K and Ueda R: Current status of immunotherapy. Jpn J Clin Oncol 46: 191-203, 2016.

25. Ohtani T, Yamada Y, Furuhashi A, Ohmura Y, Nakamura S, Kato H, Yoshikawa K and Kazaoka Y: Activated cytotoxic T-lymphocyte immunotherapy is effective for advanced oral and maxillofacial cancers. Int J Oncol 45: 2051-2057, 2014.

26. Mescher MF: Molecular interactions in the activation of effector and precursor cytotoxic T lymphocytes. Immunol Rev 146: 177-210, 1995
27. Halle S, Halle $\mathrm{O}$ and Förster R: Mechanisms and dynamics of $\mathrm{T}$ cell-mediated cytotoxicity in vivo. Trends Immunol 38: 432-443, 2017

28. Klenerman P and Oxenius A: T cell responses to cytomegalovirus. Nat Rev Immunol 16: 367-377, 2016.

29. Watanabe K, Suzuki S, Kamei M, Toji S, Kawase T, Takahashi T, Kuzushima K and Akatsuka Y: CD137-guided isolation and expansion of antigen-specific CD8 cells for potential use in adoptive immunotherapy. Int J Hematol 88: 311-320, 2008.

30. Ishiyama M, Miyazono Y, Sasamoto K, Ohkura Y and Ueno K: A highly water-soluble disulfonated tetrazolium salt as a chromogenic indicator for NADH as well as cell viability. Talanta 44: 1299-1305, 1997.

31. Kuzushima K, Hayashi N, Kimura H and Tsurumi T: Efficient identification of HLA-A*2402-restricted cytomegalovirusspecific CD8(+) T-cell epitopes by a computer algorithm and an enzyme-linked immunospot assay. Blood 98: 1872-1881, 2001.

32. Wills MR, Carmichael AJ, Mynard K, Jin X, Weekes MP, Plachter B and Sissons JG: The human cytotoxic T-lymphocyte (CTL) response to cytomegalovirus is dominated by structural protein pp65: Frequency, specificity, and T-cell receptor usage of pp65-specific CTL. J Virol 70: 7569-7579, 1996.

33. Dasari S and Tchounwou PB: Cisplatin in cancer therapy: Molecular mechanisms of action. Eur J Pharmacol 740: 364-378, 2014.

34. Galandrini R, Capuano C and Santoni A: Activation of lymphocyte cytolytic machinery: Where are we? Front Immunol 4: 390, 2013.

35. Shen DW, Pouliot LM, Hall MD and Gottesman MM: Cisplatin resistance: A cellular self-defense mechanism resulting from multiple epigenetic and genetic changes. Pharmacol Rev 64: 706-721, 2012.

36. Geary SM, Lemke CD, Lubaroff DM and Salem AK: The combination of a low-dose chemotherapeutic agent, 5-fluorouracil, and an adenoviral tumor vaccine has a synergistic benefit on survival in a tumor model system. PLoS One 8: e67904, 2013.

37. Robert C, Thomas L, Bondarenko I, O'Day S, Weber J, Garbe C, Lebbe C, Baurain JF, Testori A, Grob JJ, et al: Ipilimumab plus dacarbazine for previously untreated metastatic melanoma. $\mathrm{N}$ Engl J Med 364: 2517-2526, 2011.

38. Hattori T, Mine T, Komatsu N, Yamada A, Itoh K, Shiozaki H and Okuno K: Immunological evaluation of personalized peptide vaccination in combination with UFT and UZEL for metastatic colorectal carcinoma patients. Cancer Immunol Immunother 58: 1843-1852, 2009.

39. Sato Y, Fujiwara T, Mine T, Shomura H, Homma S, Maeda Y, Tokunaga N, Ikeda Y, Ishihara Y, Yamada A, et al: Immunological evaluation of personalized peptide vaccination in combination with a 5-fluorouracil derivative (TS-1) for advanced gastric or colorectal carcinoma patients. Cancer Sci 98: 1113-1119, 2007.

40. Masuzawa T, Fujiwara Y, Okada K, Nakamura A, Takiguchi S, Nakajima K, Miyata H, Yamasaki M, Kurokawa Y, Osawa R, et al: Phase I/II study of S-1 plus cisplatin combined with peptide vaccines for human vascular endothelial growth factor receptor 1 and 2 in patients with advanced gastric cancer. Int J Oncol 41: 1297-1304, 2012

41. Iinuma H, Fukushima R, Inaba T, Tamura J, Inoue T, Ogawa E, Horikawa M, Ikeda Y, Matsutani N, Takeda K, et al: Phase I clinical study of multiple epitope peptide vaccine combined with chemoradiation therapy in esophageal cancer patients. J Transl Med 12: 84, 2014.

42. Borghaei H,Paz-Ares L, Horn L, Spigel DR, Steins M, Ready NE, Chow LQ, Vokes EE, Felip E, Holgado E, et al: Nivolumab versus docetaxel in advanced nonsquamous non-small-cell lung cancer. N Engl J Med 373: 1627-1639, 2015.

43. Motzer RJ, Escudier B, McDermott DF, George S, Hammers HJ, Srinivas S, Tykodi SS, Sosman JA, Procopio G, Plimack ER, et al; CheckMate 025 Investigators: Nivolumab versus everolimus in advanced renal-cell carcinoma. N Engl J Med 373: 1803-1813, 2015.

44. Sugiyama D, Nishikawa H, Maeda Y, Nishioka M, Tanemura A, Katayama I, Ezoe S, Kanakura Y, Sato E, Fukumori Y, et al: Anti-CCR4 mAb selectively depletes effector-type FoxP $3{ }^{+} \mathrm{CD} 4{ }^{+}$ regulatory $\mathrm{T}$ cells, evoking antitumor immune responses in humans. Proc Natl Acad Sci USA 110: 17945-17950, 2013

45. Kurose K, Ohue Y, Wada H, Iida S, Ishida T, Kojima T, Doi T, Suzuki S, Isobe M, Funakoshi T, et al: Phase Ia Study of FoxP3 ${ }^{+}$ CD4 Treg depletion by infusion of a humanized anti-CCR4 antibody, KW-0761, in cancer patients. Clin Cancer Res 21: 4327-4336, 2015 